\title{
Memory for unattended events: Remembering with and without awareness
}

\author{
ERIC EICH \\ University of British Columbia, Vancouver, British Columbia, Canada
}

\begin{abstract}
The effects of memory for unattended events-for example, events that occur while a person is asleep, anesthetized, or selectively attending to other ongoing events, as in a speechshadowing task - are rarely revealed in tests of retention that require remembering to be deliberate or intentional. Might such effects become evident in tests that do not demand awareness of remembering? Results of the present shadowing study, involving the recognition and spelling of previously unattended homophones, suggest an affirmative answer to this question.
\end{abstract}

Memory for past events can influence present actions even if one is not aware of remembering the earlier experiences. As an example, prior presentation of a word makes it more likely that college students can report that word, when later it is briefly exposed in a perceptual identification task. regardless of whether or not they recognize the word as one that had been presented before (Jacoby \& Dallas, 1981). Similarly, amnesic patients reveal effects of practice in their subsequent performance of a cognitive, perceptual, or motor skill, even though they cannot recall ever having practiced that skill (Schacter \& Tulving, 1982). These and related observations suggest that it is possible to distinguish the effects of memory for prior episodes or experiences on a person's current behavior from the person's awareness that he or she is remembering events of the past ( Jacoby, 1982; Jacoby \& Witherspoon, 1982; Moscovitch, 1982; Tulving, Schacter, \& Stark, 1982).

The aim of this article is to apply the distinction between memory and awareness of memory to the question of whether events to which one does not attend can nevertheless be remembered. Most earlier experiments relating to this question have focused on an individual's ability to recall or recognize a specific item-a spoken word, sentence, or story, for example-as having occurred in a specific stituation--for instance, while the person was asleep (e.g., Aarons, 1976; Evans, 1972), anesthetized (e.g., Cherkin \& Harroun, 1971; Trustman, Dubovsky, \& Titley, 1977), or preoccupied with other incoming items, as in a speech-shadowing

This article was prepared with the aid of Grant U0298 from the Natural Sciences and Enginecring Research Council of Canada. The research it reports was performed while the author was a visitor in the Department of Psychology at the University of California, Los Angeles. I thank Robert Bjork and Thomas Wickens for helping to make my visit to UCLA a memorable one, and Janet Metcalfe, Roddy Roediger, and Larry Jacoby for their valuable comments and suggestions. Requests for reprints should be addressed to the author at the Department of Psychology, University of British Columbia, Vancouver, British Columbia V6T 1Y7, Canada. task (e.g.. Moray, 1959; Norman. 1969). Memory as measured in these experiments is deliberate or inten. tional, in that the person must necessarily be aware that he or she is remembering a particular past event (Jacoby \& Dallas. 1981; Jacoby \& Witherspoon, 1982). Since most people appear profoundly amnesic when tested for deliberate recall or recognition of events to which they had been exposed while asleep, anesthetized, or attending to other affairs (see earlier references), it may be confidently concluded that events that are denied conscious attention are ordinarily not amenable to conscious reflection, or accessible through "aware" forms of remembering. The conclusion need not be drawn, however, that unattended events leave no lasting impression in memory and exert no enduring effect on behavior (cf. Broadbent, 1971; Glucksberg \& Cowen, 1970; Neisser. 1976; Shiffrin \& Schneider, 1977). The possibility remains that even though the effects of memory for unattended events may not-and probably cannot-be revealed in tests of retention that require remembering to be deliberate or intentional, such effects might become manifest in tests that do not demand awareness of remembering.

The experiment detailed in this article was designed to explore the possible dissociation between memory and awareness of memory for unattended events. It relied on materials and tasks that resembled the ones employed in a recent study by Jacoby and Witherspoon (1982), which explored the dissociation between memory and awareness of memory for attended events in amnesics as well as in normals. Because the methods of the present experiment paralleled those used by Jacoby and Witherspoon, a synopsis of their study seems in order.

Participants in Jacoby and Witherspoon's (1982) study were five college students and an equivalent num. ber of amnesic Korsakoff patients. In the first phase of the study, the interpretation of a homophone was biased by having the subjects hear it in the context of a question that was to be answered (e.g., "Name a musical instrument that employs a reed")-a task that requires 
attention to and analysis of the meaning of the homophone. The bias was always toward the less common interpretation of the homophone when heard in isolation.

The influence of the prior presentation of the homophone on its later interpretation was indexed by means of a spelling test given in the second phase of the study. Jacoby and Witherspoon (1982) reasoned that if the prior presentation is remembered and influences later interpretation, a spelling in line with the less common interpretation of a homophone should be more probable for homophones that had been biased toward that interpretation in the first phase of the study than for ones that had not been previously presented. They further reasoned that an influence of memory on the spelling of a word would not necessarily require subjects to be aware that they were remembering the prior presentation of that word. Such awareness, however, would be required in the test of recognition memory that occupied the third and final phase.

Three key findings emerged from the Jacoby and Witherspoon (1982) study. First, the memory performance of the amnesic patients was very poor when measured in relation to recognition, an "aware" form of remembering. Whereas the students correctly classified as old .76 of the homophones that had appeared in the context of biasing questions, the corresponding hit rate for the patients was .25; neither the students nor the patients falsely recognized as old any homophones that had not been presented during the question phase. Second, the memory performance of the patients was very good-better, in fact, than that of the studentswhen assessed in terms of spelling, a type of test that did not demand deliberate remembering. For the patients, the probability of spelling a homophone in line with its less common interpretation was .63 for objectively old homophones and .21 for objectively new ones; for the students, the corresponding values were .49 and .20 . Third, performance in the recognition test was independent of performance in spelling: for patients and students alike, the conditional probability of a recognition hit in the third phase of the study, given that spelling had been biased by memory in the second phase, did not differ significantly from the unconditional probability of recognition.

To summarize, it appears that the prior attended presentation of a word has a marked influence on its subsequent interpretation and spelling, regardless of whether or not the word is correctly classified as old in a test of recognition memory. Furthermore, the fact that amnesics and normals reveal opposite patterns of recognition and spelling performance suggests that the two tests reflect fundamentally different aspects of memory functioning. In particular, whereas recognition of an objectively old word requires the recognizer to be aware of its prior presentation, an influence of memory on the spelling of a word does not necessarily demand delib. erate remembering. By extension, it is possible that although an effect of memory for the prior unatended presentation of a word may not be evident in performance on a later test of recognition memory, such an effect might be revealed through the subject's subsequent spelling of that word.

To cast this possibility in more concrete terms, suppose a subject is asked to shadow a prose passage that is being played on one auditory channel, and is concurrently presented with "critical" pairs of words, such as "taxi-FARE" and "movie-REEL," on the other, nonshadowed channel. As these examples suggest, the second member of each critical pair is a homophone, and the first is a word that biases the less common interpretation of the homophone with which it is paired. Suppose further that, shortly after the shadowing task, the subject is given a surprise test of recognition memory for the contents of the nonshadowed channel. For this purpose, the subject is read a list that consists, in part, of equal numbers of objectively old and new homophones-that is, homophones that either had or had not been presented on the nonshadowed channel-and is asked to discriminate between the two types of test items. Finally, suppose that following the recognition test, a second list comprising chiefly objectively old and new homophones is read to the subject, whose task is to spell each item aloud. Given the situation sketched above, might the subject spell significantly more old than new homophones in line with the homophones' less common interpretations, and yet fail to reliably discriminate between the two types of items in the test of recognition memory-a test that, unlike spelling, presumably requires conscious reflection upon events that had been denied conscious attention? An answer to this question was sought in the present study.

\section{METHOD}

Subjects

Sixteen students of introductory psychology at the University of California, Los Angeles, earned course credit through their participation in the experiment. Criteria for subject selection were intact hearing and fluency in English.

\section{Materials}

The materials of main concern consisted of 32 homophones, drawn from published norms (Galbraith \& Taschman, 1969). Drawing was random, with two restrictions: first, that the normative probability of spelling a homophone in line with its less common interpretation (e.g., "FARE" as opposed to "FAIR") not be less than .10 or more than .40 ; second, that the number of letters required in spelling a homophone remain constant, regardless of the interpretation-more or less common-given the homophone.

The selected homophones were divided into two types: old homophones $(\mathrm{N}=16)$, which were recorded on sound tape for the purpose of unattended presentation to the subjects, and new homophones $(N=16)$, which were reserved for use as lures or control items in subsequent tests of retention. The normative probability of uncommon spelling averaged 240 for both the old and the new homophones.

At recording, every old homophone was paired with a word that was intended to bias its less common interpretation (e.g. "taxi-l"ARE"); the resulting critical pairs are listed in the first two columns of Table 1 . The complete set of 16 critical pairs was recorded a total of eight times, in a different random order 
Table 1

Critical Pairs and Homophones Appearing in the Recognition and/or Spelling Tests

\begin{tabular}{|c|c|c|c|c|c|}
\hline \multirow{2}{*}{\multicolumn{2}{|c|}{$\begin{array}{c}\text { Critical Pairs } \\
\text { (modifier-OLD HOMOPHONE) }\end{array}$}} & \multicolumn{4}{|c|}{ Homophone Type/Homophone Status } \\
\hline & & \multirow{2}{*}{$\frac{\text { Old/Tested }}{\text { FARE (.13) }}$} & \multirow{2}{*}{$\begin{array}{l}\text { Old/Untested } \\
\text { BRAKE }(.10)\end{array}$} & \multirow{2}{*}{$\begin{array}{l}\text { New/Tested } \\
\text { BEET }(.13)\end{array}$} & \multirow{2}{*}{$\frac{\text { New/Untested }}{\text { BARE }(.13)}$} \\
\hline taxi-FARE & disc-BRAKE & & & & \\
\hline movie-REEL & casy-PREY & REEL (.18) & PREY $(.13)$ & POLL (.18) & GAIT (.13) \\
\hline bartlett-PEAR & window-PANE & $\operatorname{PEAR}(.20)$ & PANE (.15) & SEAM (.18) & HERE $(.23)$ \\
\hline deep-SEA & catalina-FERRY & SEA $(.20)$ & I.ERRY $(.20)$ & TALE: $(.20)$ & WAIST (.23) \\
\hline cotton-BALE & sneak-PEEK & BALE $(.28)$ & PEEK $(.30)$ & PIER (.23) & $\operatorname{ROLE}(.25)$ \\
\hline daily-MAIL & prison-CELL & MAIL $(.30)$ & CELL $(.32)$ & SOLE $(.28)$ & WON $(.25)$ \\
\hline youngest-SON & garage-SALE & $\operatorname{SON}(.30)$ & SALE $(.35)$ & MAUL $(.32)$ & HEEL (.33) \\
\hline last-WEEK & strong-STEEL & WEEK (.33) & STEEL (.37) & GROAN $(.40)$ & PAIL $(.37)$ \\
\hline
\end{tabular}

Note-All homophones appeared in the spelling test; those listed in columns marked "tested" also appeared in the preceding test of recognition. Normative probabilities of uncommon spelling, derived from Galbraith and Taschman (1969), are enclosed in parentheses.

of pairs each time, at a 4-sec/pair rate (i.e., 1 sec of speech pe: modifier, $1 \mathrm{sec}$ of speech per old homophone, and $2 \mathrm{sec}$ of silence separating one pair from the next).

Repetitions of the 16 critical pairs were bordered by 8 noncritical pairs, which served as buffer material. Each noncritical pair consisted of a modifier "cue" and a nonhomophone "target" (e.g., "hilton-HOTEL"), and was recorded once at a 4-sec rate. Of the 8 noncritical pairs, 4 (primacy pairs) preceded the first critical pair and 4 (recency pairs) followed the last critical pair.

As the critical pairs were bordered by noncritical pairs, so were the noncritical pairs bordered by letters. Specifically, the alphabetic sequence $A, B, C, \ldots Z$ was recorded once in advance of the noncritical primacy pairs and again at the conclusion of the noncritical recency pairs; in both instances, the rate of recording was 1 letter/sec. Thus, the order in which the materials specified above were recorded was (1) letters, (2) noncritical primacy pairs, (3) repeated critical pairs, (4) noncritical recency pairs, and (5) letters again.

All of the materials mentioned thus far were recorded on a reel of sound tape using the two left tracks (front and back) of a quadraphonic recorder. On the same reel of tape, but using the two right tracks (front and back), was recorded an 850-word excerpt of a humorous essay (Trillin, 1982) at an average rate of 85 words/min. The essay was recorded in the author's voice, as were the materials that had been taped on the twin left tracks.

Recordings on the left and right tracks were synchronized to begin and end at about the same time. Since the essay and the critical pairs were taped on different tracks, and since the critical pairs were bordered by buffer material (letters and noncritical pairs), recording of the essay commenced about $40 \mathrm{sec}$ before the appearance of the first critical pair and continued for about $40 \mathrm{sec}$ after the appearance of the last such pair.

\section{Design and Procedure}

The subjects were individually tested by the author in each of the experiment's three phases: presentation, recognition, and spelling.

At the outset of the presentation phase, the subject was told that his or her task was to shadow, or to repeat aloud and verbatim, an essay that would be presented on the right speaker or channel of a pair of stereo headphones. The subject also was told that he or she would be tested for comprehension and retention of the essay, and that during the shadowing, extraneous information of an unspecified nature would be presented on the left channel. It was explained that the primary purpose of the experiment was to investigate the influence of this extraneous information on an individual's ability to shadow, comprehend, and retain narrative material.

After these inital instructions had been presented, the subject was fitted with stereo headphones that were connected to the quadraphonic recorder via an extension jack equipped with separate volume controls for each headphone channel. These controls had been preset to deliver information to the right (shadowed) and left (nonshadowed) channels at sound levels that averaged approximatcly 72 and $64 \mathrm{~dB}$, respectively.

On completion of shadowing and removal of the headphones, the subject was asked to generate a short (1-min) spoken synopsis of the shadowed essay. Next, the subject was told that a secondary purpose of the experiment was to examine his or her retention of words that had been presented on the nonshadowed or unattended channel. A test of recognition memory was then given, in which the author spoke a word and the subject was asked to state aloud whether the word was old or new (i.e., had or had not been presented on the unattended channel) and to give a confidence rating. In making these recognition statements, the subject was asked to refer to a hand-held card containing the printed choices: 1 = definitely old, $2=$ probably old, $3=$ guessing old, $4=$ guessing new, $5=$ probably new, $6=$ definitely new. Thirty-two words were included in the recognition test; of these, 8 were old homophones, 8 were new homophones, 4 were old nonhomophones (target items from two noncritical primacy pairs and from two noncritical recency pairs), and 12 were new nonhomophones. The old and new homophones that were included in the test of recognition memory are listed in the third and fifth columns of Table 1, respectively; these words, together with the old and new nonhomophones, were presented for recognition testing in one randomly determined order. The test was subject paced, and the subject's recognition statements were noted in writing by the author.

Following the recognition test, the subject was asked to spell a series of words spoken by the author. A total of 64 words, representing four classes of items, were included in the spelling test; of these, 16 were old homophones, 16 were new homophones, 8 were old nonhomophones (target items from all eight noncritical pairs), and 24 were new nonhomophones. Within each class, half of the words had and half had not been included in the preceding test of recognition memory. The old and new homophones that appeared in the spelling test are shown in the third through sixth columns of Table 1 ; these words, together with the old and new nonhomophones that were to be spelled, appeared in a single random sequence. If the subject, when probed with either an old or a new homophone, voiced uncertainty as to which spelling to give, the subject was instructed to state the first spelling that came to mind. The test was subject paced, and the subject's spellings of test words were recorded in writing by the author. The subject was thoroughly debriefed on completion of the spelling test.

\section{RESULTS}

\section{Recognition and Spelling of Unattended Homophones}

Not surprisingly, the subjects performed poorly in a situation that demanded deliberate remembering of 
earlier unattended events-the test of recognition memory. As is evident in the first row of Table 2, the mean proportions of objectively old and new homophones to which subjects said "old" were essentially equivalent [old $=.398$, new $=.383: F_{1}(1,15)<1 ; F_{2}(1,14)<1$, where $F_{1}$ and $F_{2}$ signify separate analyses in which subjects $\left(F_{1}\right)$ and homophones $\left(F_{2}\right)$ were treated as random effects]. Equivalence was also evident in the mean confidence ratings that were given to the two types of test items [old $=3.773$, new $=3.945: F_{1}(1,15)$ $\left.=1.419, \mathrm{MSe}=.167, \mathrm{p}>.10 ; \mathrm{F}_{2}(1,14)<1\right]$.

Although the results of the recognition test are consistent with the claim, made by many researchers (e.g., Neisser, 1976; Norman, 1969), that there is little or no long-term retention of unattended events, the results of the spelling test suggest a different conclusion. As is shown in Table 2, the probability of spelling a homophone (such as "FARE") in line with its less common interpretation was higher if the item had been presented on the unattended channel in the context of an appropriate modifier (such as "taxi") than if it had not been presented before [old $=.348$, new $=.234: F_{1}(1,15)=$ $16.969, \mathrm{MSe}=.012, \mathrm{p}<.01 ; \mathrm{F}_{2}(1,27)=4.688, \mathrm{MSe}^{*}=$ $.022, \mathrm{p}<.05] .1,2$ Neither the "status" of a homophone (i.e., whether an item had or had not appeared in the preceding test of recognition memory) nor the interaction of homophone status with homophone type (old vs. new) had a reliable effect on spelling performance $\left(F_{1} s\right.$ and $\left.F_{2} s<1\right]$.

Why should the spelling but not the recognition of a homophone be influenced by its prior unattended presentation? One possible answer, discussed earlier, is that effects of memory for unattended events may obtain only in situations that do not require awareness of remembering, and spelling is one such situation. By this account, spelling differs in kind from an awarenessdemanding test of recognition. Alternatively, it is possible that the critical difference between these tests is a matter of sensitivity or degree. That is, it could be argued that the spelling measure has a lower "threshold" than does recognition, and hence is more sensitive to the detection of small amounts of stored information, or weak memory traces (see Kellogg, 1980). If only a difference in sensitivity is involved, successful performance of a relatively difficult, high-threshold test should ensure success on a relatively easy, low-threshold test. However, if awareness of remembering is critical, it should be possible to demonstrate that performance on a memory test that demands deliberate remembering and performance on one that does not are independent of one another, so that performance on one test cannot be predicted on the basis of performance on the other (see Jacoby, 1982).

Two types of analyses were carried out with a view to distinguishing between these alternative accounts. For purposes of the first analysis, a $2 \times 2$ contingency table was constructed, with the factors being (1) recognition hit versus miss of an objectively old homophone in the second phase of the experiment and (2) biased or uncommon versus unbiased or common spelling of the same homophone in the third phase. A total of 128 observations (16 subjects $\times 8$ old homophones per subject) were entered into the table, and were analyzed by means of a chi-square test to measure the degree of dependence between recognition memory and bias in spelling. The obtained chi-square value was well short of that required for statistical significance $\left[\chi^{2}(1)=1.602\right.$, $\phi=.112]$. For purposes of the second analysis, the observed joint probability of recognizing an objectively old homophone and of spelling that item in line with its less common interpretation was determined for each subject, and was then compared with the same subject's expected joint probability of recognition and biased spelling. ${ }^{3}$ Although the mean observed probability exceeded the corresponding expected score (.196 vs. .163 ), the difference was not reliable $[\mathrm{t}(13)=1.644$, $\mathrm{p}>.10]$.

The results of these two analyses argue against the idea that spelling is simply a more sensitive or lower threshold measure of memory for unattended items than is recognition. Performance on one test was independent of performance on the other, so that it was not necessary for an objectively old homophone to be recognized in order for its spelling to be biased by memory. Evidence of memory for unattended items was restricted to spelling, a type of test that does not logically require awareness of remembering (cf. Jacoby \& Witherspoon, 1982).

\section{Recognition and Spelling of \\ Attended Homophones}

To aid interpretation of the results reviewed in the last section, additional data were collected on what will be called the attended presentation control condition.

Table 2

Mean Proportions of Unattended Homophones Recognized as Old and Spelled in Line With Their Less Common Interpretations

\begin{tabular}{|c|c|c|c|c|c|c|c|c|}
\hline \multirow[b]{3}{*}{ Test } & \multicolumn{8}{|c|}{ Homophone Type/Homophone Status } \\
\hline & \multicolumn{2}{|c|}{ Old/Tested } & \multicolumn{2}{|c|}{ Old/Untested } & \multicolumn{2}{|c|}{ New/Tested } & \multicolumn{2}{|c|}{ New/Untested } \\
\hline & Mean & SD & Mean & SD & Mean & SD & Mean & SD \\
\hline $\begin{array}{l}\text { Recognition } \\
\text { Spelling }\end{array}$ & $\begin{array}{l}.398 \\
.352\end{array}$ & $\begin{array}{l}.238 \\
.189\end{array}$ & .344 & .148 & $\begin{array}{l}.383 \\
.219\end{array}$ & $\begin{array}{l}.235 \\
.174\end{array}$ & .250 & .137 \\
\hline
\end{tabular}


The aim of this condition was to discover why the size of the "spelling effect"-the difference in probability of uncommon spelling between objectively old and new homophones-was so much smaller in the present study $(.348-.234=.114)$ than in the one reported by Jacoby and Witherspoon (1982) (.42 for amnesics, .29 for students). Although the two studies differ in many methodological details, the most striking difference occurs in the initial or presentation phase of each experiment. Recall that in Jacoby and Witherspoon's study, the uncommon interpretation of a homophone was biased by having subjects (amnesics or students) hear it in the context of a question that was to be answered. As noted earlier, this is a task that requires conscious attention to and analysis of the meaning of the homophone. In the present study, in contrast, the uncommon interpretation of a homophone was biased by presenting both it and an appropriate modifier on an unattended auditory channel. Is it the case, then, that attention adds something even when memory is measured by means of a test such as spelling that does not demand deliberate remembering?

To answer this question, 16 UCLA undergraduates were asked to memorize a list composed chiefly of pairs of related words in anticipation of a later test of retention. The contents of the list were identical to the one that had been presented on the unattended channel in the study whose results were summarized in the preceding section. Thus, the list consisted of eight spaced repetitions of the 16 critical (modifier-OLD NONHOMOPHONE) pairs presented in Table 1, with letters and noncritical (modifier-OLD NONHOMOPHONE) pairs serving as buffer material both at the beginning and at the end of the list. The list was presented at rates of $4 \mathrm{sec} /$ pair and $1 \mathrm{sec} /$ letter via the left channel of a pair of stereo headphones; throughout presentation of the list, the right channel remained silent. Immediately after list presentation, the subjects were tested first for recognition and then for spelling, in a manner identical to that described earlier; a debriefing session followed the spelling test.

From the results given in Table 3 , it is clear that the prior attended presentation of a homophone had a profound effect on both its later recognition and on its subsequent interpretation and spelling. In comparison with objectively new homophones, old homophones were far more often recognized $\left[F_{1}(1,15)=52.822\right.$.
$\mathrm{MSe}=.108, \mathrm{p}<.01 ; \mathrm{F}_{2}(1,14)=162.631, \mathrm{MSe}=.018$, $\mathrm{p}<.011$ and far more often spelled in line with their less common interpretations $\left[F_{1}(1,15)=74.624\right.$, MSe $=.027, p<.01 ; F_{2}(1,27)=23.066$, MSe $=.042$, $p<.01]$. regardless of whether they had or had not appeared in the preceding test of recognition memory $\left[F_{1}(1,15)=3.073, \mathrm{MSe}=.016, .10>\mathrm{p}>.05 ; \mathrm{F}_{2}(1,27)\right.$ $<1]$. It is also clear that the spelling effect observed under conditions of attended presentation $[(.633+.570)$ $-(.227+.273)=.352]$ is much more robust than that obtained under conditions of unattended presentation (.114). Thus, attention does indeed seem to add something even when memory is measured by spelling, an ostensibly "unaware" form of remembering. The importance of this conclusion will be commented upon in the next section.

\section{DISCUSSION}

The results reported here are significant in several respects. First, the finding that the prior unattended presentation of a homophone had a reliable influence on its subsequent interpretation and spelling suggests that unattended information is subject to some degree of deep, semantic analysis. This suggestion has, of course, been made before (e.g., Corteen \& Wood, 1972; Lackner \& Garrett, 1972; Lewis, 1970; Marcel, 1983; for dissenting views, see Newstead \& Dennis, 1979, and Wardlaw \& Kroll, 1976). For instance, MacKay (1973), in a study that was in some respects similar to the present one, found that the interpretation of a homophone could be biased by presenting an appropriate modifier in an unattended auditory message. In MacKay's case, homophones were presented on the attended channel, whereas in the present study, both homophones and their modifiers appeared on the unattended channel. This difference notwithstanding, both the "on-line" priming effect observed by MacKay and the long-term spelling effect obtained here are compatible with the idea that unattended information is at least partially processed at the semantic level.

The second point of interest relates to the first, and it is that, although semantic processing of unattended information may sometimes be partial, it is seldom complete. This too is a statement with precedents in the literature (e.g. Treisman \& Riley, 1969; Treisman, Squire, \& Green, 1974). In the present study, support

Table 3

Mean Proportions of Attended Homophones Recognized as Old and Spelled in Line With Their Less Common Interpretations

\begin{tabular}{|c|c|c|c|c|c|c|c|c|}
\hline \multirow[b]{3}{*}{ Test } & \multicolumn{8}{|c|}{ Homophone Type/Homophone Status } \\
\hline & \multicolumn{2}{|c|}{ Old/Tested } & \multicolumn{2}{|c|}{ Old/Untested } & \multicolumn{2}{|c|}{ New/Tested } & \multicolumn{2}{|c|}{ New/Untested } \\
\hline & Mean & $\mathrm{SD}$ & Mean & SD & Mean & SD & Mean & $\mathrm{SD}$ \\
\hline Recognition & .883 & .140 & & & .039 & .075 & & \\
\hline Spelling & .633 & .174 & .570 & .137 & .227 & .172 & .273 & .104 \\
\hline
\end{tabular}


for this statement is provided by the finding that, although the prior unattended presentation of a homophone had a reliable effect on its later interpretation and spelling, the prior attended presentation of the same item produced a much more robust spelling effect. Conscious attention at presentation thus seems to be useful, but not necessary, for finding an effect of memory on spelling (cf. Kellogg, 1980).

The third point follows from the first two, and concerns an apparent, although little appreciated, paradox that exists in the attention and memory literature. The paradox is this: If unattended events are at least partially processed at a semantic level, and if semantic processing promotes long-term event memory (Craik \& Lockhart, 1972), why are unattended events difficult, if not impossible, to remember, as other investigators have argued (e.g., Neisser, 1976; Norman, 1969)? One possible resolution of this paradox hinges on what is meant by the word "remember." If the word is defined as meaning "to bring back to mind by an effort" (Jacoby \& Witherspoon, 1982, p. 300), and is identified with an individual's ability to reflect upon prior incidents or to recognize previously presented items as fainiliar, then unattended events may indeed be impossible to remem. ber: As a rule, people cannot consciously recall or recognize events to which they have not consciously attended. If, however, the meaning of "remember" is expanded to encompass functions of memory, such as spelling, that can operate in the absence of awareness of earlier experience, then attention may not be a necessary condition for subsequent recollection. That is to say, deliberate or intentional forms of remembering may require conscious attention to and analysis of an event, whereas remembering without awareness may not. Ideas closely related to the one just suggested have been expressed by Kunst-Wilson and Zajonc (1980) in connection with their recent research on the development of affective preferences for subliminal stimulus objects (also see Seamon, Brody, \& Kauff, 1983), by Jacoby and Witherspoon (1982) in their discussion of active and passive stages of perceptual processing, and by Johnson (1983) in her description of a new multistore model of memory; to my knowledge, hers is the only modern model that explicitly allows for the long-term storage and retrieval of unattended information.

Although the present results are suggestive of a dissociation between memory and awareness of memory for unattended events, they leave many questions unanswered. In aid of an example, recall that in the present experiment, homophones included in the spelling test were spoken to subjects by the same person whose voice had appeared on the unattended channel. Is this procedure necessary, or would the spelling effect, as measured by the difference in probability of uncommon spelling between objectively old and new homophones, survive a change of speaker's voice? Also, is the influence of memory on spelling stronger when there are many, rather than few, opportunities for unobtru- sive exposure, and weaker at long than at short delays between exposure and spelling? And if exposure occurred in the context of deep sleep or general anesthesia, would the resulting pattern of recognition and spelling performance resemble the one revealed in the present shadowing study? Answers to these and related questions would help define the nature of the dissociation observed here, and delineate the conditions under which it can be obtained. More important, they may add to our understanding of the relation of attention to memory, and aid in the development of a unified theoretical approach to learning and remembering, both with and without awareness.

\section{REFERENCES}

AArons, L. (1976). Sleep-assisted instruction. Psychological Bulletin, 83, $1-40$.

Broadbent, D. E. (1971). Decision and stress. New York: Academic Press.

Cherkin, A., \& Harroun, P. (1971). Anesthetics and memory processes. Anesthesiology, 34, 469-474.

ClARK, H. H. (1973). The language-as-fixed-effect fallacy: A critique of language statistics in psychological research. Journal of Verbal Learning and Verbal Behavior, 12, 335-359.

Conteen, R. S., \& Wood, B. (1972). Autonomic responses to shock-associated words in an unattended channel. Journal of Experimental Psychology, 94, 308-313.

Craik, F. I. M., \& Lockhart, R. S. (1972). Levels of processing: A framework for memory research. Journal of Verbal Learning and Verbal Behavior, 11, 671-684.

Evans, F. J. (1972). Hypnosis and sleep: Techniques for exploring cognitive activity during sleep. In E. Fromm \& $\mathbf{R}$. Shor (Eds.), Hypnosis: Research developments and perspectives. Chicago: Aldine/Atherton.

Galbraith, G. G., \& Taschman, C. S. (1969). Homophone units: $A$ normative and methodological investigation of the strength of component elements. Journal of Verbal Learning and Verbal Behavior, 8, 737-744.

Glucksbend, S., \& Cowen, G. N. (1970). Memory for nonattended auditory material. Cognitive Psychology, 1, 149-156.

JACOBY, L. L. (1982). Knowing and remembering: Some parallels in the behavior of Korsakoff patients and normals. In L. S. Cermak (Ed.), Memory and amnesia. Hillsdale, NJ: Erlbaum.

JACOBY, L. L., \& DAlLAs, M. (1981). On the relationship between autobiographical memory and perceptual learning. Journal of Experimental Psychology: General, 110, 306-340.

JACOBY, L. L., \& Witherspoon, D. (1982). Remembering without awareness. Canadian Journal of Psychology, 36, 300-324.

Johnson, M. K. (1983). A multiple-entry, modular memory system. In G. H. Bower (Ed.), The psychology of learning and motivation (Vol. 17). New York: Academic Press.

KELLOGG, R. T. (1980). Is conscious attention necessary for longterm storage? Journal of Experimental Psychology: Human Learning and Memory, 6, 379-390.

Kunst-Wilson, W. R., \& Zajonc, R. B. (1980). Affective discrimination of stimuli that cannot be recognized. Science, 207, 557-558.

LACKNER, J. R., \& GARRETT, M. F. (1972). Resolving ambiguity: Effects of biasing context in the unattended ear. Cognition, 1, 359-372.

LEWIS, J. L. (1970). Semantic processing of unattended messages using dichotic listening. Journal of Experimental Psychology, 85, $225-228$.

MacKAY, D. G. (1973). Aspects of the theory of comprehension, memory and attention. Quarterly Journal of Experimental Psy. chology, 25, 22-40. 
MARCEL, A. J. (1983). Conscious and unconscious perception: An approach to the relations between phenomenal experience and perceptual processes. Cognitive Psychology, 15, 238-300.

Moray, N. (1959). Attention in dichotic listening: Affective cues and the influence of instructions. Quarterly Journal of Experimental Psychology, 11, 56-60.

Moscovitch, M. (1982). Multiple dissociations of function in amnesia. In L. S. Cermak (Ed.), Memory and amnesia. Hillsdale, NJ: Erlbaum.

NeISSE r, U. (1976). Cognition and reality. San Francisco: Freeman.

NEWSTEAD, S. E., \& DENNIs, 1. (1979). Lexical and grammatical processing of unshadowed messages: $A$ re-examination of the MacKay effect. Quarterly Journal of Experimental Psychology, 31, 477-488.

Norman, D. A. (1969). Memory while shadowing. Quarterly Journal of Experimental Psychology, 21, 85-93.

Schacter, D. L., \& Tulving, E. (1982). Memory, amnesia, and the episodic/semantic distinction. In R. L. Isaacson \& N. E. Spear (Eds.), Expression of knowledge. New York: Plenum.

Seamon, J. G., Brody, N., \& Kauff, D. M. (1983). Affective discrimination of stimuli that are not recognized: Effects of shadowing, masking, and cerebral laterality. Journal of Experimental Psychology: Learning, Memory, and Cognition, 9, 544-555.

Shiffrin, R. M., \& Schneider, W. (1977). Controlled and automatic human information processing: II. Perceptual learning, automatic attending, and a general theory. Psychological Re view, 84, 127-190.

Treisman, A., \& Riley, J. G. (1969). Is selective attention selective perception or selective response? A further test. Journal of Experimental Psychology, 79, 27-34.

Treisman, A., Squire, R., \& Green, J. (1974). Semantic processing in dichotic listening? A replication. Memory \& Cognition, 2, 641-646.

Triluin, C. (1982). U. S. Journal: Pembroke Park, Florida. New Yorker, 58(8), 134, 136, 139-143.

Trustman, R., Dubovsky, S., \& Tituey, R. (1977). Auditory perception during general anesthesia-Myth or fact? International Journal of Clinical and Experimental Hypnosis, 25, 88-105.

Tulving, E., Schacter, D. L., \& Stark, H. A. (1982). Priming effects in word-fragment completion are independent of recognition memory. Journal of Experimental Psychology: Learning, Memory, and Cognition, 8, 336-342.
Wardlaw, K. A., \& Kroll, N. E. A. (1976). Autonomic responses to shock-associated words in a nonattended message: A failure to replicate. Journal of Experimental Psychology: $\mathrm{Hu}$ man Perception and Performance, 2, 357-360.

Wtckens, T. D., \& KePpeL, G. (1983). On the choice of design and of test statistic in the analysis of experiments with sampled materials. Journal of Verbal Learning and Verbal Behavior, 22, 296-309.

\section{NOTES}

1. The symbol MSe* signifies the mean square error term derived from a two-factor (homophone type $\mathrm{x}$ homophone status) analysis of covariance in which the normative and observed probabilities of uncommon speling served as the control and the criterion measures, respectively.

2. Based on the results of these $F_{1}$ and $F_{2}$ tests, the min $F^{\prime}$ for the difference in probability of uncommon spelling between objectively old and new homophones is 2.960. With 1 and 37 degrees of freedom, this quasi-F value is only marginally significant $(.10>p>.05)$, which implies that the observed difference might not simultaneously generalize across both different subjects and different homophones (see Clark, 1973). According to Wickens and Keppel (1983), however, F1 may be a more appropriate test statistic than min $F^{\prime}$ provided that (1) the items or materials employed in an experiment are "balanced" or sampled systematically so as to make them more representative of the populations from which they are drawn, and (2) the error terms underlying the values of $F_{1}$ and $F_{2}$ are roughly equivalent. Both of these conditions were met in the present study: Homophones included in either or both the recognition and spelling tests were sampled systematically with respect to both word length and normative probability of uncommon spelling, and the error terms contributing to the observed $F_{1}$ and $F_{2}$ values were quite comparable (.012 and .022 , respectively).

3. The expected joint probability was found for each subject by multiplying his or her simple probability of recognition by his or her simple probability of biased spelling. The data for two subjects, whose expected joint probability was zero, were excluded from further analysis.

(Manuscript received January 17, 1983 ; revision accepted for publication December 16,1983 .) 